\title{
CHARLES DE SECONDAT EN EL ESTADO DE PARTIDOS, O DEL PLURIPARTIDISMO COMO MATERIALIZACIÓN MODERNA DEL PRINCIPIO DE DIVISIÓN DE PODERES ${ }^{1}$
}

\author{
JAVIER RUIPÉREZ ALAMILLO \\ Catedrático de Derecho Constitucional \\ Universidad de A Coruña
}

TRC, núm. 46, 2020, pp. 211-240

ISSN 1139-5583

\begin{abstract}
SUMARIO
I. La compatibilidad de la teoría de la división de poderes con el principio de soberanía popular. II. La separación de poderes como garantía introducida por el poder constituyente soberano en los Códigos Constitucionales. III. El papel de la justicia constitucional en la defensa del principio de separación de poderes. IV. La crisis de los partidos políticos en el marco de propuestas autodenominadas de «regeneración democrática». V. El estado de partidos como razón de la pretendida obsolescencia de la doctrina de la división de poderes. VI. La reformulación de la doctrina: check and balances entre las fuerzas mayoritarias y las de oposición.
\end{abstract}

\section{LA COMPATIBILIDAD DE LA TEORÍA DE LA DIVISIÓN DE PODERES CON EL PRINCIPIO DE SOBERANÍA POPULAR}

No dejaría de ser un simple ejercicio de constatación de lo obvio comenzar recordando que el principio de división de poderes se presenta como uno de los contenidos fundamentales del Estado Constitucional y del concepto mismo de Constitución. Lo es, en efecto, desde la compresión de esta última que nos ofrece

1 El presente artículo se publica en el marco del acuerdo de colaboración firmado entre la Revista Teoría y Realidad Constitucional y el Centro de Estudios de Partidos de la UNED para la publicación de trabajos de investigación sobre partidos políticos. 
el concepto formalista y neutro de los Códigos Constitucionales, que es al que, en los albores de la presente centuria, apeló el «europeísmo a ultranza», y tanto por parte de los prácticos de la política, como por parte de los profesionales universitarios de las Ciencias Jurídicas, para tratar de atribuir a aquel «Proyecto de Tratado por el que se instituye una Constitución para la Unión Europea», — que por su propio origen y naturaleza, tan sólo podría ser entendido como una norma de Derecho Internacional, siquiera sea especial y particular ${ }^{2}$, y cuya fuerza jurídica obligatoria y vinculante se deriva del Derecho Constitucional de los diversos Estados que integran el ente supraestatal europeo 3 - en la medida en que este documento jurídico iba a contener los dos elementos a los que se refiere el celebérrimo artículo 16 de la Declaración de Derechos del Hombre y del Ciudadano de 1789. Pero lo es también del concepto político de Constitución, en la medida en que, como aclaró Pedro De $\mathrm{Vega}^{4}$, en dicho precepto se dan cita los supuestos medulares sobre los que se edificó la Democracia Constitucional, y que, en definitiva, no son otros que los de tratar de dar, de modo permanente, auténtica realidad y efectividad, con su ponderada combinación, a las viejas ideas de «Democracia», «Libertad»y, como correctivo necesario de ambas, que, por lo demás, ya había sido exigido en la Atenas clásica por Solón y, todavía de un modo más explícito, Aristóteles, «Igualdad».

No es éste el lugar oportuno para extendernos en el, indudable, hecho de que se encuentra firmemente asentado en el imaginario colectivo la idea de que la formulación de la división del ejercicio del poder político ordinario se debe a de Secondat ${ }^{5}$. Aunque no está de más advertir que ello no es más que una simplificación, que, además, incurre en una cierta injusticia. Ha de tomarse en cuenta que lo que sucede es que se está obviando que, con anterioridad a la formulación de Montesquieu, este problema había sido ya abordado por otros pensadores políticos y jurídicos. Lo hizo, en efecto, y ya en 1324, Marsilio de Padua en su célebre «Defensor Pacis», del que von Gierke ${ }^{6}$ llegó a decir que tenía como principal mérito haber establecido un modelo jurídico-político que se presenta como uno de los más claros precedentes teóricos del moderno Estado Constitucional. Y, a nuestro juicio, no está de más recordar que si esto es así, ello, $-\mathrm{y}$ dando buena prueba de la importancia que tuvo el pensamiento iusnaturalismo contractualista en la forja teórico-ideológica del constitucionalismo moderno ${ }^{7}$, y que, en último

2 Cfr., sobre este particular, y por todos, J. Ruipérez Alamillo, La «ciudadanía europea» y sus implicaciones para el Derecho Constitucional (Un estudio de Teoría del Estado y de la Constitución sobre la moderna Unión de Estados de Derecho Internacional europea), México, 2018.

3 En este sentido, aunque referido en general al problema de la eficacia jurídica obligatoria y vinculante del Derecho Internacional, cfr. B. Mirkine-Guetzévitch, Derecho Constitucional internacional (1933), Madrid, 2008.

$4 C f r$. P. De Vega, «En torno al concepto político de Constitución», en M.A. García Herrera (Dir.) y otros, El constitucionalismo en la crisis del Estado social, Bilbao, 1997.

5 Cfr. Montesquieu, Del espíritu de las leyes (1748), Madrid, 1985.

6 Cfr. O. von Gierke, Teorías políticas de la Edad Media (1881/1900), Madrid, 1995.

$7 C f r$., por todos, P. DE VEGA, «Mundialización y Derecho Constitucional: la crisis del principio democrático en el constitucionalismo actual», REP, n. ${ }^{\circ} 100,1998$. 
extremo, es lo que permite afirmar, por ejemplo a Smend ${ }^{8}$ que la teoría del contrato social es la única que permite comprender adecuadamente el proceso de fundamentación y conceptualización del Estado Constitucional—-, se debe al hecho de que, al partir de la concepción de que la Comunidad Política es una creación de los hombres, y, en consecuencia, que era a éstos, y únicamente a ellos, a quien correspondía decidir tanto los modos y las formas en que querían ser gobernados en el futuro, como sobre las cuestiones diarias sobre el gobierno de aquélla ${ }^{9}$, no hacía más que afirmar la soberanía del Pueblo. Tampoco debería olvidarse que también con anterioridad al celebérrimo escrito de Montesquieu, había procedido ya John Locke a proponer que el poder político ordinario fuese dividido en Poder Legislativo, Poder Ejecutivo —en el que quedaban incardinados los jueces- y Poder Federativo, siendo éste en realidad un poder que se ocupaba de las relaciones exteriores del Estado.

Debemos señalar que si esto es así, no es menos cierto que, de una u otra suerte, aquella simplificación tiene una clara explicación, y justificación. Al fin y al cabo, lo que sucede es que la construcción del aristócrata liberal, y, aunque sin poder confesarlo abiertamente, gran maquiavelista (P. De Vega), francés se presenta como la más acabada perfecta, y fue, en todo caso, la que se consagraría, en el más estricto cumplimiento de aquella lógica de la mecánica del proceso constituyente que, como está generalmente aceptado (Ch. Borgeaud ${ }^{10}, \mathrm{P}$. De Vega), encontró en Wise ${ }^{11}$ su primer, y más brillante, expositor, por parte de los primeros revolucionarios liberal-burgueses en los Códigos Constitucionales. Ocurriendo, como está generalmente aceptado en la doctrina de las Ciencias del Estado y del Derecho del Estado y, naturalmente, desde la concepción del constitucionalismo moderno como una técnica de garantía de la libertad individual frente al poder político (Ch, Borgeaud, H. Heller, P. De Vega), que, en consecuencia, se presenta como sinónimo del liberalismo (K. Loewenstein, C. de Cabo, etc.), que su constitucionalización, —que, de acuerdo con la explicación del proceso constituyente realizada, en el marco de la Revolución francesa, en donde la concepción de Wise era, como indicó Zweig ${ }^{12}$, bien conocida, por los Isnard, Desmeunier, Valdruche, Romme e Isnard, y explicando de algún modo las reticencias que mostraron los democrátas y democrátas radicales a la inclusión de la

8 Cfr. R. Smend, «Constitución y Derecho Constitucional» (1928), en Constitución y Derecho Constitucional, Madrid, 1985.

9 Sobre este particular, $c f r$., por todos, P. DE VEGA, «Constitución y Democracia», en la ob. col. La Constitución española de 1978 y el Estatuto de Autonomía del País Vasco, Oñati, 1983; «En torno a la legitimidad constitucional», Estudios en homenaje al Doctor Héctor Fix-Zamudio en sus treinta años como investigador de las Ciencias Jurídicas. Derecho Constitucional, México, 1988.

10 Cfr. Ch. Borgeaud, Établissement et révision des Constitutions en Amérique et en Europe, París, 1893.

11 Cfr. J. Wise, A Vindication for the Government of the New England Churches. A Drawn from Antiquity; the Light of Nature; Holy Scripture; its Noble Nature; and from the Dignity Divine Providence has put upon it, Boston, 1717.

12 Cfr., en este sentido, y por todos, E. ZweIG, Die Lehre vom Pouvoir Constituant. Ein Beitrag zum Staatsrecht des franzöischen Revolution, Tubinga, 1909. 
referencia a la separación de poderes en el art. 16 de la Declaración de Derechos del Hombre y del Ciudadano de 1789, venía, de una u otra suerte, impuesta por el contenido del momento de la libertad-, se concibió, de modo muy principal, como la articulación de un mecanismo técnico para tratar de hacer real y efectiva esa esfera de libertad individual que se había reconocido a los ciudadanos del Estado (F. Battaglia, K. Loewenstein, N. Pérez Serrano), mediante el establecimiento de, por decirlo en palabras del propio Montesquieu, sistema en el en el que "el poder frene al poder", en cuyo seno "los tres poderes permanecerán así en reposo o inacción, pero, como por el movimiento necesario de las cosas, están obligados a moverse, se verán forzados a hacerlo de común acuerdo». No es menester, asimismo, dedicar mucho espacio a tratar de averiguar cuál era la verdadera intención del barón de La Brède al teorizar la división de poderes y, al mismo tiempo, proponer su articulación, siguiendo la visión que él tenía del sistema británico, como un sistema de pesos y contrapesos entre un Poder Ejecutivo — que se atribuía al monarca y a sus Ministros—, un Poder Legislativo — constituido, siguiendo el modelo británico, como un órgano bicameral, en el que una de las Cámaras tendría como misión la de expresar la voluntad de los ciudadanos del Estado en general, mientras que la otra quedaba reservada a los miembros de la aristocracia-, y un Poder Judicial — que, expresando ese gran temor que el aristócrata liberal sentía hacia una judicatura sometida al rey (F. Tomás y Valiente), estaría atendido por unos jueces independientes, y, como auténtica novedad respecto de la situación existente en el Antiguo Régimen, claramente separados de los cuerpos administrativos al servicio del monarca-, al que, de cualquiera de las maneras, anulará desde el punto de vista político al configurarlo como un poder políticamente neutro y que el juez no es más que la boca que pronuncia la ley. Y ello, por cuanto que poco importa determinar si tenía, o no, razón Althusser cuando defiende la idea de que, en realidad, y frente a la opinión común, la doctrina de Montesquieu es en extremo conservadora. Como tampoco tiene una particular importancia que nos inclinásemos por dar la razón a quienes consideran que el esquema propuesto respondía al deseo mostrado por Montesquieu, — que, en este punto se apartaba, y grandemente, del criterio mantenido por de Maquiavelo-, por apartar al Pueblo de los asuntos públicos en lógica y coherente consecuencia con esa innegable desconfianza, o temor, a las multitudes que siempre han demostrado las doctrinas del elitismo político. Interpretación ésta que vendría avalada por el contundente aserto realizado por Montesquieu en el sentido de que el «pueblo es admirable cuando realiza la elección de aquéllos a quienes debe confiar parte de su autoridad porque no tiene que tomar decisiones más que a propósito de cosas que no puede ignorar y de hechos que caen bajo su dominio de los sentidos. Sabe perfectamente cuándo un hombre ha estado a menudo en la guerra o ha tenido tales o cuales triunfos; por ello está capacitado para elegir un general. Sabe cuándo un juez es asiduo [...]: cosas suficientes para que elija un pretor. [...]. Son éstos hechos de los que se entera mejor en la plaza pública que el monarca en su palacio. Pero, en cambio, no sabría llevar los 
negocios ni conocer los lugares, ocasiones o momentos para aprovecharse debidamente de ellos. [...] Del mismo modo que la mayoría de los ciudadanos que tienen suficiencia para elegir no la tienen para ser elegidos, el pueblo, que tiene capacidad para darse cuenta de la gestión de los demás, no está capacitado para llevar la gestión por sí mismo».

\section{LA SEPARACIÓN DE PODERES COMO GARANTÍA INTRODUCIDA POR EL PODER CONSTITUYENTE SOBERANO EN LOS CÓDIGOS CONSTITUCIONALES}

Lo que, de verdad, nos interesa es tratar de explicar la centralidad que tiene el principio de división de poderes en el marco del moderno Estado Constitucional, y la verdadera virtualidad que, al margen de meras consideraciones formales, adquirió la constitucionalización de este principio siguiendo los esquemas conceptuales propuestos por Montesquieu. Y ello, por cuanto que es tan sólo, — como puso de manifiesto De $\mathrm{Vega}^{13}$ — , desde la cabal y ponderada comprensión de esto desde donde únicamente podremos alcanzar una correcta comprensión de la realidad del principio de división de poderes en el momento actual.

En cuanto al primero de estos interrogantes, creemos que no ha de existir dificultad alguna para que todos, pero principalmente quienes se dedican profesionalmente al estudio de las Ciencias del Estado, —entre las cuales, nosotros, en contra de lo afirmado, p. ej., por Rehm ${ }^{14}$, pero dando plena validez a las construcciones de Georg Jellinek, consideramos incluidas todas aquellas disciplinas jurídicas que tienen por objeto el conocimiento de los caracteres y de las notas jurídicas del Estado y de las relaciones del mismo, señaladamente el Derecho Constitucional, el Derecho Administrativo y el Derecho Internacional Público-, y las Ciencias del Derecho del Estado, _ entre las cuales el Derecho Constitucional se presenta no como su único contenido posible (G. Meyer), pero sí, y de forma difícilmente cuestionable, como su contenido central ${ }^{15}$ - , para descubrir el motivo por el cual la división de poderes ocupa esa posición preeminente tanto para el concepto neutro y formal, como para el concepto político de los Códigos Constitucionales. Bastará, para ello, con actuar con el concepto técnico, moderno y actual de los Códigos Jurídico-Políticos Fundamentales, que es, en definitiva, el que se corresponde con el que, a lo largo de toda su obra, escrita y no escrita, Pedro De Vega identificó con el rótulo de «concepto liberal-burgués de Constitución», y al que se le reconocía una validez y vigencia plena (H.P. Schneider, P.

13 Cfr. P. De Vega, «Tendencias y problemas del constitucionalismo español actual», en Evolución de la organización político-constitucional en América Latina (1950-1975), México, 1979, vol. II.

14 Cfr. H. ReHm, Geschichte der Staatfrechtswissenschaft, Friburgo-Leipzig, 1896.

$15 C f r$., en este sentido, y a título de mero ejemplo, F. STIER-SomLO, Reichstaatsrecht, Berlín-Leipzig, 1927. 
De Vega, P. Lucas Verdú, etc.), por lo menos hasta que el Estado Constitucional mismo, - y muy particularmente cuando el mismo adopta la forma de Estado Constitucional democrático y social-, ha comenzado a ser discutido como consecuencia de la mundialización o globalización ${ }^{16}$.

$Y$ es que, en efecto, no puede olvidarse que desde este concepto técnico, moderno y actual, —que es, por lo demás, el que han aceptado también, por ejemplo, Maunz, Starck, Schneider, Zagrebelsky, García-Pelayo, Ollero, Morodo, García de Enterría, Rubio Llorente o Cascajo-, se entiende que únicamente es posible hablar de una verdadera Constitución para referirse a aquellos instrumentos de gobierno que surgen a raíz de un momento histórico determinado: las grandes revoluciones liberal-burguesas americana y francesa de finales del s. XVIII, y que tienen un concreto substrato teórico común: la confrontación de los supuestos ideológicos del pensamiento político liberal y los presupuestos del pensamiento político democrático, de suerte tal que sólo podrán considerarse como verdaderos Códigos Constitucionales aquellos Textos Constitucionales que, procediendo a la previa organización de los poderes de la colectividad y a la determinación de los modos en que éstos han de decidir, se encuentran definidos e inspirados por los principios democrático (la Teoría Democrática del Poder Constituyente), liberal (defensa de la libertad individual a través de los institutos, inseparables, de las declaraciones de derechos y la separación de poderes) y de supremacía constitucional (sujeción, por igual, pero, y como señaló correctamente el Tribunal Constitucional español en su STC 101/1983 ${ }^{17}$, no de idéntica manera $^{18}$, de gobernantes y gobernados a la Constitución ${ }^{19}$, y concordancia del Derecho ordinario con ella). La Constitución, como producto típico, junto con los Códigos del Derecho Técnico Ordinario, del racionalismo jurídico, se presenta, desde una tal óptica, como un documento escrito, formal y solemne (A. Esmein-H. Nézard, K. Hesse, M. García-Pelayo), aprobado y sancionado por una autoridad

16 Cfr., a este respecto, y por todos, D. VALAdÉs, «Consideraciones sobre el Estado Constitucional, la ciencia y la concentración de la riqueza», en A. Guerra-J. F. Tezanos (Eds.) y otros, Alternativas para el s. xxi. I Encuentro Salamanca, Madrid, 2003. En el mismo sentido, vid., por todos, E. García, El Estado Constitucional ante su «Momento Maquiavélico» Madrid, 2000.

17 Cfr. STC 101/1983, FJ 3. .

18 A este respecto, y a título de mero ejemplo, aunque de manera fundamental para conocer cómo ha interpretado el supremo custodio constitucional español el distinto modo en que los gobernados — que, en el marco del moderno Estado Constitucional, pueden hacer todo aquello que el Derecho no les prohíbe expresamente - y los gobernantes, que, como la gran conquista del Estado Constitucional, —y que, en opinión, de, $v$. $g r$, un McIlwain constituye el único elemento que permite en realidad diferenciar el constitucionalismo antiguo (es decir, el que, según él, operaba en el mundo clásico y medieval) y el constitucionalismo moderno (es decir el que surge como con los grandes procesos revolucionarios liberal-burgueses de finales del s. XVIII)—, pueden tan sólo llevar a cabo aquellas conductas que la Constitución y el Derecho, como, y en la comprensión de este problema mantenida por Krabbe [ $c f r$. H. KRABBE, Die moderne Staatslehre, Haag, 1919] y Kelsen [cfr. H. Kelsen, Teoría General del Estado, México, 1979, 15. a ed.], único soberano posible es en el marco de un Estado Constitucional ya operante, les autoriza, de forma expresa, a desarrollar, y que, de cualquiera de las maneras, sería muy conveniente que fuese recordado.

19 Cfr. P. De Vega, La reforma constitucional y la problemática del Poder Constituyente, Madrid, 1985. 
superior competente: el Pouvoir Constituant du Peuple, que, recogiendo los supuestos basilares del pensamiento político liberal, explicitados en el celebérrimo artículo 16 de la Declaración de Derechos del Hombre del Ciudadano, pretende, de manera consciente (C. Schmitt, R. Smend, K. Stern), establecer, de una vez y para siempre, una ordenación racional de la vida política del Estado.

Fácil es deducir, a la vista de lo anterior, el motivo por el cual, como se ha señalado, existe un acuerdo generalizado en la identificación de los términos «constitucionalismo»y «liberalismo». Como también, ha de ser fácil de comprender el motivo por el que Heller considera que declaración de derechos y división de poderes se presentan como dos instrumentos inescindibles, así como el que forme parte del imaginario colectivo, y firmemente asentada en él, que la constitucionalización de la división de poderes tuvo como primigenia y fundamental finalidad la de proporcionar un mecanismo técnico-jurídico merced al cual los hombres y mujeres podrían gozar pacíficamente de los derechos que les eran reconocidos en cuanto que ciudadanos del Estado, y frente a la actuación de los titulares del poder político ordinario en este último. Lo que, de cualquiera de las maneras, será fácil de entender. Lo será, en efecto, con sólo tomar en consideración el proceso por el cual hizo su entrada en la Historia el Estado Constitucional. En este sentido, basta con recordar que debemos, entre otros muchos, a Battaglia, Loewenstein, Pérez Serrano y De Vega la observación de que lo propio de la primera manifestación estructural concreta del Estado Constitucional, el Estado burgués de Derecho, fue el que la primera tarea que abordaron los revolucionarios liberal-burgueses americanos ${ }^{20}$, y ya en la etapa colonial, así como, con posterioridad, y bajo la influencia de lo hecho por los estadounidenses (G. Jellinek), los franceses fue, justamente, $-\mathrm{y}$ desde la indiscutible aceptación de los esquemas conceptuales puestos en circulación por el reverendo Wise- la de proceder al reconocimiento de la existencia de una esfera de libertad individual absoluta, que se concretaba en el plano normativo en las declaraciones de derechos fundamentales. Sólo en un momento posterior, y como mecanismo de garantía de aquéllos, es cuando se procede, con la aprobación del Texto Constitucional, a la organización del Estado sobre la base de la división de poderes. E interesa advertir que así sucedió desde el mismo momento en que, como nos enseñó Jellinek $^{21}$, se inició la Historia de lo que los europeos solemos identificar con el nombre de derechos fundamentales, y en el Continente americano como derechos humanos, esto es, de los derechos y libertades que se disfrutan no por la condición de ser hombres, sino, por el contrario, de ser ciudadanos de una determinada Comunidad Política estatal ${ }^{22}$. Lo que, de cualquiera de las maneras, resulta

20 Cfr., en este sentido, y por todos, G. Jellinek, La Declaración de los Derechos del Hombre y del Ciudadano (1895/1904), México, 2000.

21 Cfr. G. Jellinek, Sistema dei diritti pubblici subjetivi (1892), Milán, 1912.

22 Importa, en todo caso, señalar que lo anterior no es, ni mucho menos, una mera especulación teórica carente de toda virtualidad práctica, sino que, muy al contrario, y dando plena satisfacción a esa doble 
incuestionable con sólo tomar en consideración que que el documento escrito formal y solemne con el que realmente empieza a la Historia de los derechos fundamentales; el Bill of right of Virginia, fue aprobado el 12 de junio de 1776, mientras que la Constitución de Virginia lo fue el 29 del mismo mes y año.

Mayores complicaciones plantea la segunda de las cuestiones a las que antes nos referíamos, es decir, la de cuál fue la verdadera virtualidad que tuvo la constitucionalización de la división de poderes. Y ello, por cuanto que si, generalmente, se ha hecho especial mención al transcendental papel que juega la consagración en el más alto nivel normativo del Estado de la construcción del barón de La Brède para tratar que los ciudadanos gozasen del mayor grado de libertad posible, a lo que, sin embargo, no se le ha prestado una especial atención es a las circunstancias jurídico-políticas e ideológicas que condujeron a una tal solución en el contexto del ejercicio de la función constituyente de acuerdo, de una manera muy básica, con la teorización de su mecánica debida a Sieyès, a cuyo conocimiento, por lo demás, nunca puede, ni debe, renunciar el constitucionalista, por lo menos si éste es consciente de su propia función ${ }^{23}$. Tanto más, cuanto que el desconocimiento de los procesos de conceptualización y fundamentación del Estado Constitucional puede, de manera lamentable, conducirnos a repetir esa dramática circunstancia de la primera mitad de la pasada centuria, en donde, como escribió el propio De Vega, «Tergiversando los planteamientos weberianos se ha producido una identificación arbitraria entre los términos de legitimidad y legalidad, como consecuencia del abandono incomprensible de los principios de la soberanía popular y la voluntad general, sin cuya mediación esa identificación

dimensión de la Teoría del Derecho Constitucional como ciencia conceptual y ciencia práctica que ya le había sido, de uno u otro modo, atribuida por G. Jellinek, resulta una cuestión decisiva para poder abordar de un modo cabal y ponderado la tarea de buscar soluciones en el ámbito del Derecho Constitucional positivo. Convenir en ello no debería ser muy complicado. Y el momento actual de la integración europea nos ofrece un magnífico ejemplo al respecto. Y es que, innecesario debiera ser aclararlo, es tan sólo tomando en consideración la distinción realizada por Wise entre la libertad natural, la que corresponde a los hombres y mujeres por ser tales, y la libertad civil, que aparece vinculada a la idea de pertenencia a un determinado Estado Constitucional, como podremos determinar si la llamada «Declaración Europea de Derechos Fundamentales», que se incorporó, finalmente, al llamado «Tratado de Lisboa», atribuyéndole ya esa eficacia jurídica obligatoria y vinculante, constituyen realmente unos verdaderos derechos fundamentales, o si, por el contrario, y en tanto en cuanto que la Unión Europea no es todavía un Estado Constitucional único, se trata, pese a su nombre, de una Declaración de derechos humanos establecida por una norma de un Derecho Internacional Público aunque, eso sí, especial y particular. Lo que, como a nadie debería ocultársele, tiene un especial interés práctico en la medida en que de la decisión que se adopte, se derivará un muy distinto régimen jurídico para la citada Declaración europea de Derechos Fundamentales.

23 A este respecto, creemos oportuno traer a colación las palabras de P. De Vega, en el sentido de que «aunque se haya dicho esta mañana [se refiere a la del 16 de noviembre de 2007 , cuando se inició la «Jornada»] que la Historia de las ideas no forma el contenido esencial de la disciplina y naturalmente se nos haya asegurado, pero como presupuesto, de alguna manera sí tenemos que tenerlo ya, y yo lo que no creo es que ese presupuesto se tenga si, de alguna manera, no se estudia y no se pone en los programas». Vid. P. DE VEGA, J. Cano Bueso, J. A. Portero Molina y J. Ruipérez Alamillo, «Comisión sobre el Estado Autonómico: P. De Vega -Mod.—; J. Cano Bueso; J.A. Portero Molina y J. Ruipérez Alamillo», de las «actas de la jornada sobre orientación y método del derecho constitucional», TRC, n. ${ }^{\circ} 21,2008$. 
carece por completo de sentido. Ya en la época de Weimar constataba Heller con estupor el hecho de que la organización constitucional, y las explicaciones consiguientes de la misma, se estuvieran olvidando del papel central de las nociones clásicas de soberanía popular y de voluntad general, que comenzaban a ser tratadas como conceptos extraños a la Teoría Constitucional. Las protestas contra ese olvido, que fueron todavía numerosas en los años inmediatamente posteriores a la Segunda Guerra Mundial, están quedando subsumidas ahora en el más oprobioso de los silencios. Es difícil encontrar en la actualidad, entre los teóricos de la democracia y de la Constitución, textos en los que se denuncien los riesgos derivados de los intentos de reducir la democracia a un sistema de reglas del juego, y donde se critique el colosal disparate de pretender convertir las cuestiones de legitimidad en meras cuestiones de legalidad, sin una previa fundamentación democrática de la legalidad» ${ }^{24}$.

No es éste el momento oportuno para detenernos a discutir si, como afirman, entre otros, Zweig y De Vega, tenía, o no, razón Laboulaye cuando, de modo contundente, afirmó que Sieyès «lo que hizo fue confundirlo todo, embrollarlo todo $\mathrm{y}$, a la postre, perderlo todo» ${ }^{25}$. Como, y de forma inconcusa, tampoco lo es para recrearnos en la en la célebre polémica en torno a si, como sostiene Bacot, Sieyès operaba con el concepto de Nación en el que tan sólo estarían integrados los hombres de la generación presente en cuanto que ciudadanos activos de la Comunidad Política, o si, por el contrario, tiene razón Carré de Malberg cuando, supuestamente desde una interpretación jacobina, afirma que éste opera con un concepto de Nación que, alejándose de la concepción maquiavélica del Pueblo como un sujeto histórico, temporal, real y concreto el cual, actuando como tal y siempre en el ejercicio de la virtud política, decide libremente sobre el gobierno del Estado en cuanto que realidad histórica, temporal, real y concreta, terminaba por convertir a ésta en un sujeto ahistórico, atemporal y, de una u otra forma, mítico en el que, al igual que sucedía con la Comunidad Política misma en el mundo clásico y medieval, estarían integradas las generaciones presentes, pasadas y futuras. Aunque no está de más advertir que ha sido a la apelación a este último concepto de Nación, y desde la máxima sublimación y espiritualización de ésta, del que se sirvieron, y se siguen sirviendo hoy, los antidemócratas y antiliberales de toda especie para tratar de excluir a los ciudadanos del proceso de toma de decisiones políticas fundamentales, e incluso fingiendo ser los grandes defensores del Estado Constitucional, el cual, y en la medida en que se encuentra edificado sobre, y desde, la lógica inherente a las ideas y el principio democrático, tiene,

24 P. De VEGA, «La Democracia como proceso. (Algunas reflexiones desde el presente del republicanismo de Maquiavelo)», en A. Guerra-J. F. Tezanos (eds.) y otros, Alternativas para el s. xxi. I Encuentro Salamanca, Madrid, 2003. Para el lamento helleriano, Cfr. H. Heller, La soberanía. Contribución a la Teoría del Derecho estatal y del Derecho internacional (1927), México, 1995, 2. ${ }^{\text {ed. }}$.

25 E. Laboulaye, «Du Pouvoir Constituant»(1871), en E. Laboulaye, Questions contitutionelles, Paris, 1872 . 
como nos recordaba De Vega, uno de sus principios básicos en la idea de que los ciudadanos, que en cuanto que titulares de la soberanía individualmente considerados, y del ejercicio de la soberanía en cuanto que integrantes del Pueblo estatal, habían procedido a la aprobación del Código Constitucional, en modo alguno podrían ser excluidos del proceso de toma de decisiones políticas fundamentales una vez que ha entrado en vigor la Constitución por ellos aprobada.

Lo que nos interesa destacar, es que cuando se toma en consideración la exposición realizada por Sieyès de la mecánica del proceso constituyente, y explicándola desde lo que, por ejemplo, Hatschek ${ }^{26}$ había denominado la «Teoría revolucionaria del Poder Constituyente», lo que se descubre es que la verdadera, y más importante, virtualidad que tuvo la constitucionalización de la división de poderes es, como precisó $\mathrm{Heller}^{27}$, la de actuar como un instrumento técnico a través del cual podría materializarse la que posteriormente se presentaría como la tesis rousseauniana de la volonté générale. Afirmación ésta que no ha de encontrar dificultad alguna para que todos los estudiosos de la Teoría del Estado y del Derecho Constitucional.

No la tendrán, desde luego, todos aquellos constitucionalistas que no renuncien al conocimiento de los procesos de conceptualización y fundamentación del Estado Constitucional. Y ello, por cuanto que, si así actúan, conocerán que, como pusieron ya de relieve Zweig, De Vega y Vanossi ${ }^{28}$, uno de los mayores aciertos de Sieyès a la hora de explicar la mecánica del proceso constituyente en el contexto de la democracia representativa fue, justamente, su intento por tratar de conciliar la lógica de la democracia representativa defendida por el Barón de Montesquieu y la doctrina de la volonté générale teorizada, desde la lógica de la democracia de la identidad, por el «Ciudadano de Ginebra». Distinción ésta, y en modo alguno es ocioso resaltarlo, de la que, no obstante el hecho de que la misma se ha visto, de una u otra suerte, —y de un modo muy singular como consecuencia de la interpretación hobbesiana que realizó Schmitt de la formulación del abate revolucionario ${ }^{29}$, y que terminan, contrariando la concepción que él tenía en 1928 sobre la reforma constitucional como una auténtica facultad constitucional limitada, por convertir al poder de reforma en un sujeto facultado para ejercer una dictadura soberana ${ }^{30}$ obscurecida por la interpretación que se ha generalizado del hecho de que tanto

26 Cfr. J. HATSCHEK, Allgemeine Staatsrecht auf rechtvergleichender Grundlage, Leipzig, 1909, t. II; Deustches und preussischen Staatsrecht der Deutschen Reichs, Berlín, 1922, vol. I. Sobre esta distinción, cfr., también, N. Pérez Serrano, «El Poder Constituyente» (1947), en N. Pérez Serrano, Escritos de Derecho Político, Madrid, 1984, vol. I.

27 Cfr. H. Heller, «Il concetto di legge nella Constituzione di Weimar» (1927), en H. Heller, La sovranità et altri scritti sulla Dottrina del Diritto e dello Stato, Milán, 1987.

28 Cfr. J. R. A. Vanossi, Teoría Constitucional. I. Teoría Constituyente. Poder Constituyente: fundacional; revolucionario; reformador, Buenos Aires, 1975.

29 Cfr., de un modo muy singular, C. Sснмітт, «La dictadura. Desde los comienzos del pensamiento moderno de la soberanía hasta la lucha de clases proletaria» (1921/1978), en C. SCHMITT, Ensayos sobre la dictadura. 1916-1932, Madrid, 2013.

30 A este respecto, $c f r$., por todos, J. Ruipérez Alamillo, «Una primera aproximación a la problemática de la eficacia jurídica de las leyes de reforma constitucional», en V. A. WONG Meraz, C. León Bastos 
Sieyès como La Fayette exigieran que los miembros de la Asamblea de revisión recibiesen del Cuerpo Electoral un poder especial, y específico para llevar a cabo la modificación formal del texto de la Constitución ${ }^{31}$, se deriva la eficacia, y que, a diferencia de lo que sucede desde $2003^{32}$, fue perfectamente entendida por el Tribunal Constitucional bajo la presidencia de Manuel García-Pelayo ${ }^{33}$, que ha de tener la distinción Poder Constituyente-poderes constituidos tan pronto como el Código Constitucional ha sido aprobado y ha entrado en vigor, siempre, lógicamente, en condiciones de normalidad constitucional.

Sea de ello lo que sea, lo que nos interesa destacar es que al tratar de articular la mecánica del proceso constituyente desde la conciliación de los presupuestos del pensamiento del barón de La Brède con los de Rousseau, lo que Sieyès hizo fue, en último extremo, potenciar algo que ya se encontraba implícito en la obra de Montesquieu. Y que ha de ser fácil de entender, comprender y compartir. Bastará, en efecto, con tomar en consideración que, como no podría ser de otra manera, de Secondat, como buen liberal, había formulado su construcción actuando desde el aparato conceptual y categorial elaborado por el iusnaturalismo contractualista. De un modo más concreto, elaboró Montesquieu su tesis sobre la necesidad de dividir el ejercicio del poder político ordinario, desde los esquemas teóricos propios de la teoría del contrato social formulada no desde los presupuestos de las doctrinas del pactum subjectionis construidas desde la idea de la traslatio imperii, defendida en el medioevo por los por los Accursio, Baldo, Bartolo de Sassoferrato y Angelo Aretino, - y que son las que, sirviendo de apoyatura básica a Hobbes, se convirtieron en el fundamento último de los regímenes autocráticos en cualquiera de sus variantes: monarquía absoluta, totalitarismos, etc., que en el mundo han sido y son-, sino, por el contrario, sobre los de la teoría de la concessio imperii formuladas por los Cino, Cristóforo Parco y Zarabella ${ }^{34}$ que, en cuanto que precedente inmediato del iusnaturalismo contractualista racionalista democrático, es desde donde únicamente puede fundamentarse adecuadamente la actual estructura del Estado Constitucional (R. Smend). Lo que, como ha de ser evidente, implica que aceptaba Montesquieu la idea de que en toda Comunidad Política democrática, de la que el Estado Constitucional es su máximo exponente, toda la actividad política de gobernados y gobernantes ha de estar jurídicamente limitada por la voluntad soberana de una autoridad superior expresada normativamente en la ley.

y J. L. Sosa CARRero (coords.) y otros, La reforma constitucional y su problemática en el Derecho Comparado, México, 2017.

31 Sobre este problema, cfr., por todos, J. RuipéRez Alamillo, Reforma versus revolución. Consideraciones desde la Teoría del Estado y de la Constitución sobre los límites materiales a la revisión constitucional, México, 2014.

32 Vid. STC 48/2003, FJ 7. ${ }^{\circ}$; STC, 103/2008, FJ 4. . ; STC 31/2010, FJ 12; STC 42/2014, FJ 4. . . c).

33 Cfr. STC 76/1983, FJ 4.

34 Para la comprensión y distinción entre las doctrinas de la traslatio imperii y la concessio imperii, $c f r$, por todos, O. vON GIERKe, Giovanni Althusius e lo sviluppo storico delle teorie politiche giusnaturalische, Turín, 1974; H, Kurz, Volkssouveränitat und Volksrepräsentation, Bonn, 1965. 
$\mathrm{Y}$ es, innecesario debiera ser aclararlo, a esta idea a la que, justamente, $-\mathrm{y}$ a pesar del hecho de que no exista en el contenido formal de «De l'Esprit des Lois» referencia alguna a esa necesaria, e ineluctable y constrictiva, existencia de un poder político superior y anterior, y en el que, a la postre, y en contra de lo que se deriva de la contraposición realizada por Rehm sobre la soberanía del Estado y la de los órganos, se residencia la titularidad legítima del ejercicio de la soberanía en esa determinada Comunidad Política, a los que, en cuanto que poderes constituidos, se organizan como Poder Legislativo, Poder Ejecutivo y Poder Judicial—, responde su construcción del principio de división de poderes. De Vega, con la brillantez y rigor que siempre le caracterizaron, lo puso claramente de relieve en «La reforma constitucional y la problemática del Poder Constituyente». Así, hizo notar que «Es cierto que Montesquieu no alude nunca a lo largo de su extensa obra al poder constituyente. Sin embargo, no lo es menos que constituye una premisa tácita y perfectamente presumible en la lógica global de su pensamiento, en la medida en que la aparición de los tres poderes - [...]-, que recíprocamente se vigilan y controlan como poderes constituidos, no se concebiría sin el reconocimiento de un poder previo y superior a ellos en el que aquellos cifrarán la razón de su existencia».

Fácil resulta comprender, desde esta perspectiva, —y en modo alguno resulta ocioso reseñarlo-, el motivo por el cual Zweig y Carré de Malberg ${ }^{35}$, oponiéndose a una idea muy generalizada entre los estudiosos del Derecho Público, y muy especialmente entre los iuspublicistas españoles (ex. gr., E. García de Enterría), pudieron afirmar que puestos a buscar el verdadero antecedente teórico inmediato de la teoría democrática del Pouvoir Constituant du Peuple, el mismo ha de situarse en las especulaciones del barón de La Brède y de Montesquieu, y no en las de Rousseau. Lo que se explica fácilmente. Es menester tomar en consideración que, aunque obligados, incluso, a admitir que, como indicó Zweig, la tesis del «Ciudadano de Ginebra» sobre la soberanía popular actúa como un complemento lógico de la teoria de división de poderes del aristócrata liberal para la construcción por parte de Sieyès de la «teoría revolucionaria del Poder Constituyente», lo que jamás debiera ser olvidado es que, aunque consciente de las dificultades y problemas que tendría su puesta en marcha en el marco de los grandes Estados-Nación, lo que Rousseau defendía, siquiera fuera como modelo ideal, era la democracia de la identidad, en la que, por ser todos los integrantes del Cuerpo Político al mismo tiempo, y por igual, gobernantes y gobernados, y ejercer la soberanía en todo momento, no ha lugar a la distinción entre el Poder Constituyente soberano y los poderes constituidos, así como para proceder a la división del ejercicio, — que no, y bajo ningún concepto, de la titularidad, que sigue perteneciendo al Pueblo del Estado como titular legítimo de la soberanía ${ }^{36}$, pero

35 Cfr. R. Carré de Malberg, Teoría General del Estado, México, 1948.

36 Cfr., en este sentido, y por todos, M. KRIELE, Introducción a la Teoría del Estado. Fundamentos históricos de la legitimación del Estado constitucional democrático, Buenos Aires, 1980. 
que, siguiendo de una u otra suerte las concepciones de Nicolás de Maquiavelo como gran teórico del régimen democrático en cuanto que proceso que se pone a prueba consigo mismo ${ }^{37}$, y que tan sólo reconocía la legitimidad al ejercicio del poder absoluto por parte del gobernante en los momentos de grave crisis de la Comunidad Política (G. Sabine), sólo actúa como tal en el momento del «comienzo o al final Estado constitucional, cuando éste es creado o cuando éste es abolido» (M. Kriele), lo que, a la postre, permite decir, desde la óptica del positivismo jurídico, a un $\mathrm{Krabbe}^{38}$ y a un Kelsen que, en rigor, en el marco de un Estado Constitucional ya operante no cabe más soberanía que la de la Constitución y el Derecho-, poder político en Poder Legislativo, Poder Ejecutivo y Poder Judicial.

\section{EL PAPEL DE LA JUSTICIA CONSTITUCIONAL EN LA DEFENSA DEL PRINCIPIO DE SEPARACIÓN DE PODERES}

Conocida ya la verdadera significación del principio de división de poderes, es cuando podemos abordar el estudio de su problemática en el Derecho Constitucional actual. Y, en este sentido, no dejaría de ser un simple ejercicio de constatación de lo obvio comenzar afirmando que el mismo, y sobre todo si nos quedamos en los meros términos formales de la teorización de Montesquieu, ha experimentado una serie de transformaciones en su materialización jurídico-formal. Entre ellas, y acaso como la más significativa, por lo menos en lo que hace al constitucionalismo europeo y a todos los Estados que finalmente han optado por consagrar el que, oponiéndolo, —obviando, en todo caso, que en cuanto que racionalización del sistema americano que es (A. La Pergola), las diferencias entre el modelo difuso y concentrado no fueron nunca, como se encargó de poner de relieve el mismo Kel$\operatorname{sen}^{39}$, tan rígidas como se presumía en su explicación teórica, y que, además, hoy estas diferencias tienden a difuminarse en el ámbito del Derecho Constitucional Comparado-, al sistema de la judicial review puesto en marcha, en 1803, por el juez John Marshall, —quien no volvería ni a poner en marcha el control de constitucionalidad, ni a dejar inaplicada una ley federal, hasta el fin de su carrera judicial (D. García Belaúnde)—, con la emanación de la celebérrima sentencia del caso «Madison versus Marbury», Schmitt denominó el modelo de la jurisdicción constitucional concentrada. Nos referimos, obviamente, a aquellos Tribunales Constitucionales que, construidos, fundamentalmente, sobre las especulaciones de

37 Cfr. C. J. Friedrich, La Democracia como forma política y como forma de vida, Madrid, 1965, 2. ${ }^{a}$ ed.

38 Cfr. H. KRABBE, Lehre der Reichssouveränität: Beitrag zur Staatslebre, Groninga, 1906.

$39 C f r$. H. KELSEN, «Il controllo di costituzionalità delle leggi. Studio comparato delle Costituzioni austriaca americana» (1942), en H. Kelsen, La Giustizia Costituzionale, Milán, 1981. Sobre esta misma cuestión, cfr. D. García Belaúnde, "Kelsen en París. Un debate en torno al "modelo concentrado" », en D. GaRCÍA Belaúnde (Ed.), y otros, Hans Kelsen, Sobre la jurisdicción constitucional, Lima, 2017. 
Weyr ${ }^{40}$ y de Kelsen, hicieron su entrada en la Historia con las Constituciones checoeslovaca y austríaca, ambas de 1920, y que se generalizaría, en muy buena medida para tratar de eludir el riesgo de nuevos regímenes totalitarios (M. Cappelletti), en la Europa desde el fin de la Segunda Guerra Mundial, actúan, de una suerte u otra, como comisionados por el Poder Constituyente para el sostenimiento de su obra normativa (E. García de Enterría), y se configuran como unos órganos de carácter jurisdiccional aunque no adscritos al Poder Judicial (P. De Vega), del que, como del resto de los poderes constituidos ${ }^{41}$, es independiente ${ }^{42}$.

Y no hace falta decir que la aparición de este nuevo órgano constitucional, que supone un colosal embate a la literalidad de la construcción de Montesquieu, fue interpretado, desde concepciones jurídico-políticas claramente antidemocráticas y antiliberales (P. De Vega), por, verbi gratia, Forsthoff ${ }^{43}$ como la definitiva transformación del Estado Constitucional en un mero Estado jurisdiccional, en el que los contenidos del principio liberal, y muy especialmente la división de poderes, quedaban eliminados. Lo que, ni que decir tiene, resulta claramente inexacto por cuanto que, al tener los Tribunales Constitucionales como principal misión la de garantizar «que los poderes constituidos actúen dentro del marco y de los límites establecidos por la decisión del Constituyente tal y como quedó objetivada en las normas constitucionales» ${ }^{44}$, lo que sucede es, justamente, todo lo contrario. Pedro De Vega, con igual acierto que contundencia y rigor, lo puso claramente de manifiesto cuando, en los albores de la actual etapa constitucional española, escribió que «No merece la pena discutir la realidad, a todas luces exagerada, de ese posible «gobierno o dictadura de los jueces». Lo que interesa constatar, sin embargo, es el cambio en el significado constitucional del juez. Como guardián de la Constitución, el Tribunal Constitucional, ya no es el simple vigilante que da coherencia a los actos normativos de rango inferior con los preceptos constitucionales (en cuya esfera se sitúa el control de constitucionalidad), sino que, además, se ha convertido en el vigilante y encargado de dar coherencia a la vida estatal en su conjunto, resolviendo los conflictos entre poderes y obligando a todos ellos a cumplir los imperativos constitucionales ${ }^{45}$. De donde, sin dificultad alguna, se deduce que lejos de ser ciertas las acusaciones realizadas desde el pensamiento jurídico-político antidemocrático y antiliberal, - y no obstante el

40 Cfr. F. Weyr, «Zum Problem eines einheitlichen Rechtssystem», Archiv des öffentlichen Rechts, Bd. 23 (1908); «Das Verfassungsrecht der Tschechoslowakischen Republik», Zeitschrist für öffentliches Recht, Bd. 2, 1921.

41 Cfr. A. Bickel, The Supreme Court and the Idea of Progress, New Haven, 1979, 2. ed.; J. H. Ely, Democracy and Distrust. A Theory of Judicial Review, Cambridge, 1980.

42 Cfr. K. A. Bettermann, Die Verfassungskonforme Auslegung: Grezen und Gefabren, 1986.

$43 C f r$., a título de mero ejemplo, E. Forsthoff, «¿Estado de Derecho o Estado de los jueces?», en E. Forsthoff, Estado de Derecho en mutación. Trabajos constitucionales. 1954-1973, Madrid, 2015.

44 M. García-Pelayo, «El status del Tribunal Constitucional», REDC, n. ${ }^{\circ} 1,1981$.

45 P. De VegA, «Comentario al Título IX. Tribunal Constitucional», en la ob. col. Constitución española. Edición comentada, Madrid, 1979. 
hecho de que en no pocas ocasiones se hayan convertido en la práctica en uno de los elementos fundamentes para la generación del caos (P. De Vega)-, lo que sucede es que los Tribunales Constitucionales han servido para dar auténtica realidad y eficacia a todos y cada uno de los principios inspiradores del constitucionalismo, en la medida en que, como escribió el Maestro, «el principio liberal, basado, como señalamos en su momento, en la división de poderes y en el reconocimiento de los derechos y libertades, se traduce a nivel jurisprudencial en la asignación al Tribunal de la facultad para resolver los conflictos entre órganos y para entender del recurso de amparo. El Tribunal Constitucional se presenta así como última garantía de la división de poderes (en cuanto impide que unos órganos afectan las esferas de actuación de otros) y como salvaguarda final de los derechos y libertades. De igual manera, el principio de supremacía constitucional tiene su traducción más patente en el sistema de protección jurisdiccional, en la competencia básica de toda la justicia constitucional, que es, como se sabe, la de los recursos de inconstitucionalidad. Otro tanto cabría indicar con relación al principio democrático, que tal y como señalamos que se entiende y se integra en los ordenamientos constitucionales del presente, encuentra su mejor garantía en la propia competencia del Tribunal Constitucional para declarar la inconstitucionalidad de las leyes. La razón es evidente: una ley en contra de la Constitución, si tuviera validez, equivaldría a una reforma de la Constitución».

\section{LA CRISIS DE LOS PARTIDOS POLÍTICOS EN EL MARCO DE PROPUESTAS AUTODENOMINADAS DE «REGENERACIÓN DEMOCRÁTICA»}

De cualquiera de las maneras, no es ésta la circunstancia que nos interesa resaltar en este momento, y para dar respuesta al interrogante de si, por utilizar la expresión frecuente en el debate político, Montesquieu ha muerto en el contexto del Estado Constitucional y, además, tan pronto como éste se presentó ya, y sin ambages de ningún tipo, e incluso antes de su legalización y constitucionalización, como aquel Parteienstaat del que hablaba Triepel, y en el que, acaso como rasgo más notorio, aquel mandato libre conforme al cual, y de acuerdo ya con la teorización de Sieyès, y que, en todo caso, se convertiría en el rasgo definidor más importante de la representación política, se establecía la ficción de que el representante parlamentario, que, ahora, y a diferencia de lo que sucedía con el mandato imperativo - cuya vigencia en el momento anterior a las grandes revoluciones liberal-burguesas de finales del s. XviII, hacía que difícilmente pudiera hablarse de una auténtica representación política ${ }^{46}$ - , no podría ser revocado en

46 Cfr. G. Leibholz, Das Wesen der Repräsentation und der Gestalwand der Demokratie im 20. Jahrbundert, Berlín, 1966; P. VIRGA, Il partito nell'ordinamento giuridico, Milán, 1948. 
su mandato (A. Esmein, Ch. Müller) ${ }^{47}$, representaba a toda la nación en su conjunto (H. Heller, H. Kelsen, P. De Vega ${ }^{48}$, y que, a la postre, permitió identificar el Estado Constitucional con el Estado o el gobierno representativo mismo ${ }^{49}$, se ha visto substituido por el mandato de partido, en virtud del cual, y unido a la consagración del sufragio universal y la adopción del sistema proporcional, lo que sucede es que hoy las decisiones políticas se adoptan en el interior de los partidos políticos ${ }^{50}$. En efecto, no puede olvidarse que el fenómeno anterior fue el que, en último extremo, dio origen a que Trotta, con una plasticidad indudable, pudiera escribir que «Repetimos ciertas fórmulas por costumbre y tradición sin darnos cuenta del engaño en que incurrimos. Hablamos de soberanía del Parlamento, y sabemos perfectamente que ésta ya no existe. Hablamos de división de poderes y sabemos que ésta ha desaparecido desde el momento en que los gobiernos se han convertido en Comités de acción de las mayorías parlamentarias, y más aún, desde que aquellos y éstas dependen de las secretarías y comisiones ejecutivas de los partidos» ${ }^{51}$.

Es desde esta perspectiva, desde donde comenzará, por un lado, a proclamarse la crisis total de la división de poderes en el Estado actual, y por otro, a reivindicarse la vuelta a la concepción de ésta por de Secondat identificada con la obligada atribución de la titularidad de cada uno de los poderes constituidos a un sujeto distinto. Lo que, ni que decir tiene, se hace especialmente patente en el marco de los Estados que cuentan con el sistema de gobierno parlamentario, en el que, debido a la centralidad que se reconoce al Poder Legislativo, todos los demás órganos constitucionales se formarán atendiendo al juego de las mayorías y minorías en él.

No hace falta ser en exceso sagaz y perspicaz para comprender que en esa denuncia de la crisis absoluta de la división de poderes, así como en la demanda de volver a los esquemas formales trazados por el barón de La Brède lo que subyace, además del deseo de volver a la falaz distinción fisiocrática entre el «Estado-aparato» y la «sociedad civil»_-identificada ésta, por cierto, y tanto por parte

47 Cfr. Cfr. A. Esmein y H. NÉZARD, Élements de Droit Constitutionnel français et comparée. I. La Liberté moderne: Principes et institutions, 8. a ed., París, 1927; Ch. Müller, Das imperative und freie Mandat, Bonn, 1966.

48 Cfr. H. Kelsen, «Il problema del parlamentarismo» (1925), en H. Kelsen, Il primato del Parlamento, Milán, 1982. P. DE VEGA, «En torno a la crisis de las ideas de representación y de legitimidad en la democracia actual», en J. L. Soberanes, D. Valadés y H. A. Concha Cantú (eds.) y otros, La reforma del Estado. Estudios comparados, México, 1996.

49 Cfr., en un tal sentido, y por todos, J. S. Mill, Del Gobierno representativo, Madrid, 1985.

50 Sobre esto, cfr., por todos, R. SMEND, «La transformación del orden constitucional liberal por el sistema proporcional» (1919), en R. SMEND, Constitución y Derecho Constitucional, Madrid, 1985; H. TRIEPEL, La Constitución y los partidos políticos (1927/1930), Madrid, 2015; G. LEIBHOLZ, La rappresentazione nella democracia, Milán, 1989. E. Forsthoff, «Problemas constitucionales del Estado social» (1961), en E. ForsTHOFF, Estado de Derecho en mutación. Trabajos constitucionales 1954-1973, Madrid, 2015.

51 F. Trotta, Parlamento e Partiti como problema attuale della democracia; soluzioni costituzionali, Milán, 1964, citado por P. DE VEGA, «Prólogo» a P. De VEGA (ed.) y otros, Teoría y práctica de los partidos políticos, Madrid, 1977. 
de liberales (C. Lefort, J. Rawls), como por parte de los marxianos o neomarxianos (J. Rosemberg), siempre, y sin excepciones relevantes, con las fuerzas y poderes del mercado, esto es, con los titulares del poder económico ${ }^{52}$ - es el discurso antipartido. No es menester que nos entretengamos a indicar que, como yo aprendí del Maestro Pedro De Vega, éste, que había nacido ya con el triunfo de los grandes procesos revolucionarios de finales del s. XVIII, y desde la creencia de que la existencia de estas organizaciones vendría a impedir la satisfacción de unos supuestos intereses nacionales superiores, los cuales tan sólo podrían verse atendidos con la formación de un Gobierno que representase a todo el Cuerpo Político (G. Leibholz), había adquirido inicialmente una dimensión progresista y democrática con los discursos de los Washington, Madison, Robespierre, Saint-Just, etc., pasaría, ya en el s. XIX, a formar parte nuclear del pensamiento conservador y autoritario, y, finalmente, a adquirir su máxima expresión en el primer tercio de la pasada centuria cuando el mismo pasó a ser enarbolado, de modo fundamental, pero no exclusivo - y podríamos, en este sentido, recordar aquí las obscuras reflexiones de Radbruch ${ }^{53}$ sobre los partidos_-, por los autores más claramente antidemócratas y antiliberales, entre los que ocupan un lugar preferente Ostrogorski y Michels. Éstos, nadie puede desconocerlo, se mostrarían partidarios de la transformación del Estado de partidos, —en el que, como señalaría Thoma, «La voluntad ideal del Estado democrático es la voluntad de las organizaciones de partido dominantes en ese momento, con base en el consentimiento o la tolerancia del pueblo» ${ }^{54}$ _ , en ese «Estado-partido» (O. von Koellreuter) propio de los totalitarismos modernos en los que, desde, de un modo bien diverso a lo que define el régimen democrático, una visión unitaria y exclusivista del mundo que les lleva a la imposibilidad de reconocer el fraccionamiento y la existencia inevitable del conflicto en la sociedad (R. Dahrendorf, C. J. Friedrich), se pretendía solucionar «la separación entre la realidad política y la normativa constitucional se resolvió de esta forma con la identificación o la vinculación total de los mecanismos del Estado y los mecanismos del partido» ${ }^{55}$

E importa señalar que es, justamente, esta última manifestación del discurso antipartido la que, aunque en la mayoría de los casos de forma inconsciente, ha conocido en los primeros años de esta centuria, y principalmente en su segunda década, una nueva revitalización. Si bien, y de manera que no puede ser considerada sino paradójica, ahora en nombre de las ideas democráticas y progresistas.

52 Sobre este particular, y por comodidad, cfr., por ahora y por todos, J. Ruipérez Alamillo, De los derechos fundamentales sociales y su eficacia jurídica. Entre la jurisdicción constitucional y la voluntad constitucional (Un estudio de Derecho Constitucional Procesal con motivo de una de las propuestas de reforma de la Constitución española de 1978), México, 2018.

53 Cfr. R. Radbruch, Filosofía del Derecho (1932), Madrid, 2008.

54 Citado por H. TriePel, La Constitución y los partidos políticos, cit.

55 P. DE VEGA, «Estado social y Estado de partidos. La problemática de la legitimidad», en la ob. col. Problemas actuales del Derecho Constitucional. Estudios en homenaje a Jorge Carpizo, México, 1994. 
Nos estamos refiriendo, obviamente, a los acontecimientos vividos por doquier en 2011, y que, por ejemplo, en España se denominó «el movimiento $15 \mathrm{M}$ ».

No nos corresponde tratar de determinar hasta qué punto estos movimientos fueron el resultado de un movimiento ciudadano espontáneo, o si, por el contrario, - y en conexión directa con la problemática de la articulación práctica de la división de poderes en un mundo globalizado_-, el mismo se debía a algo orquestado a través de las nuevas redes de comunicación social, y, en todo caso, y por los mismos que habían tratado de interferir en el proceso electoral en Estados Unidos de América, en Francia, en México, etc. De la misma manera, tampoco nos corresponde a nosotros, desde luego a los efectos de este escrito, interrogarnos sobre si no hubo, siquiera inconscientemente, entre los participantes de estos movimientos no pocos cuya actuación sería reconducible a lo que Habermas había denominado «revolucionarismo aparente», o, como mínimo, a lo que Tierno Galván llamó «radicalismo estético» — caracterizado éste por cuanto que su actuación se presenta «como simple evasión estética y romántica de los compromisos que impone una realidad cruel. Se trataría entonces de simples radicalismos estéticos, cuya mayor o menor grandeza moral carece de sentido a nivel social» ${ }^{56}$ - Aunque, empero, no podríamos dejar de señalar que esta interpretación podría entenderse como justificada en tanto en cuanto que lo que el transcurso del tiempo ha demostrado es que este movimiento, que, —obviando que sigue siendo plenamente cierto el aserto de Kelsen de que «no puede dudarse que el descrédito de los partidos políticos por parte de la teoría y la doctrina del derecho político de la monarquía constitucional encubría un ataque contra la realización de la democracia. Sólo por ofuscación o dolo puede sostenerse la posibilidad de la democracia sin partidos políticos. La democracia, necesaria e inevitablemente, requiere un Estado de partidos ${ }^{57}$; así como el que, como escribió mi dilecto Maestro, la «experiencia nos enseña es que cuando los partidos desaparecen, los que le substituyen son los grupos de presión, los magnates de las finanzas o los demagogos convocación de dictadores ${ }^{58}{ }^{5}$ - , se oponía a la existencia de este tipo de organizaciones, de forma paradójica, ha dado lugar por todas partes a la creación de nuevas organizaciones políticas partidistas, así como nuevas plataformas electorales, destinadas, unas y otras, a integrarse, a través del instituto de representación en el marco del Parteienstaat, en los centros de decisión y acción política de la Comunidad Política, y muy singularmente en el Parlamento y el Gobierno.

Lo que nos interesa, es tan sólo señalar que existen unas patentes concomitancias entre la nueva denuncia de la desaparición fáctica de la división de poderes como consecuencia de los partidos, y la que hicieron en el primer tercio del s. $\mathrm{xx}$ los autores antidemócratas y antiliberales. Nadie discute, ni podría hacerse, 1970.

56 P. De VEGA, «Para una teoría política de la oposición», Boletín Informativo de Ciencia Política, n. ${ }^{\circ} 5$,

57 H. Kelsen, «Esencia y valor de la Democracia» (1920-1921), en H. Kelsen, Esencia y valor de la Democracia, Barcelona, 1977, 2. ${ }^{\mathrm{a}}$ ed.

58 P. De Vega, Legitimidad y representación en la crisis de la Democracia actual, Barcelona, 1998. 
que no faltaba una cierta razón a quienes protagonizaron las revueltas de 2011, y como consecuencia de la actitud mostrada, por doquier, por no pocos dirigentes de las organizaciones partidistas. Para nadie, en efecto, puede ser un misterio que en la protesta de aquellos días, lo que, de una u otra suerte, subyacía era la toma en consideración de ese peligro real que existe en toda democracia representativa, y que, en última instancia, fue denunciada por Berlia cuando, refiriéndose al problema de la naturaleza del poder de reforma constitucional, señaló que «los elegidos dejan de ser los representantes de la nación soberana [o, en su caso, del Pueblo soberano], para convertirse en los representantes soberanos de la nación» ${ }^{59}$, -y que es, en último extremo, y refiriéndose también al ejercicio de la función constituyente como actividad jurídica reglada y limitada, había conducido a Pergolesi $^{60}$ a defender que, por su propia importancia objetiva, y por cuanto no es siempre presumible que porque las organizaciones partidistas que habían recibido el mayor número de votos en los anteriores comicios generales deseen revisar la Constitución, el contenido material de la misma responda a los intereses de los ciudadanos en el momento en el que aquélla se efectúa ${ }^{61}$, toda reforma, incluso aunque ello no estuviera previsto en el Código Constitucional, habría de ser sometido al voto directo de los ciudadanos en referéndum; lo que, en todo caso, y en opinión de Borgeaud, haría que la normativa constitucional aprobada gozase de una mayor vigencia y eficacia práctica—, volverán a argüir el lema de «no nos representan», del que, nadie puede ignorarlo, con tanto éxito se habían aprovechado Hitler y Mussolini, y al que, por influencia de Herrera Oria, habían apelado en la España de 1933 la CEDA y Lerroux.

De cualquiera de las maneras, lo que ha de ser reseñado es que en el implícito mensaje antipartido que esconde este lema, lo que subyace, aunque con toda probabilidad de modo inconsciente en el supuesto de la mayoría de los protagonistas de los acontecimientos de 2011, es el mismo mensaje que encerraba la célebre «ley de hierro de la oligarquía» de Michels, conforme a la cual, y como contenido medular y basilar de la misma, lo que sucede en el marco de la democracia representativa en régimen de partidos es que la estructura piramidal de las organizaciones partidistas no hacen más que favorecer el distanciamiento de los dirigentes del partido respecto de sus propias bases. Circunstancia que, a la postre, y, se dirá, pese a los correctivos que se establecen, por ejemplo, en el artículo $6 .^{\circ}$ de la Constitución española en el sentido de que su «estructura interna y su funcionamiento deberán ser democráticos» —y que debieran haber conducido a residenciar el

59 G. Berlia, «De la compétence constituante», Revue de Droit Public, 1945.

60 Cfr. F. Pergolesi, Diritto Costituzionale, Padua, 1972, 15. ${ }^{a}$ ed., 2. ${ }^{a}$ reimpr., t. I.

61 En este mismo sentido, cfr., por todos, C. Cereti, Corso de Diritto Costituzionale italiano, Turín,

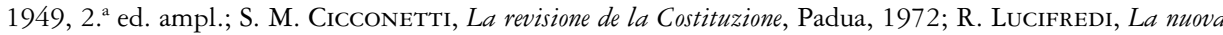
Costituzione italiana, Milán, 1952; M. Ruini, Il referendum popolare e la revision della Costituzione, Milán, 1953; R. CAlzada Conde, La reforma constitucional y las mutaciones en el ordenamiento constitucional (Tesis Doctoral, inédita) Salamanca, 1987, vol. II. 
control de los mismos en el ámbito de la jurisdicción constitucional, y no en el de la ordinaria (P. De Vega, R. Morodo, P. Lucas Murillo de la Cueva)—, termina haciendo que el partido con representación parlamentaria pase a defender los intereses concretos y coyunturales de sus dirigentes, que, además, serán los que ocupen los puestos políticos en el aparato institucional del Estado, incluso cuando los mismos puedan ser contrarios a los de sus militantes, simpatizantes y votantes. Lo que, ni que decir tiene, supone dar plena validez a aquella idea expresada ya por Lord Bryce de que «La organización traiciona la voluntad del pueblo» ${ }^{62}$.

También va a ser igual la receta que ofrecían a esta tendencia, siempre patológica, a la oligarquización. En efecto, tanto los antidemócratas y antiliberales de los primeros años del s. xx, y que no tenían otra intención que demostrar la imposibilidad misma del régimen democrático (P. De Vega), como quienes, - pareciendo hacerse eco de la contraposición elaborada por Burdeau ${ }^{63}$ entre democracia gobernante y democracia gobernada-, asumen el discurso antipartido de éstos en los primeros años de la presente centuria aunque, eso sí, presuntamente en nombre de aquella la libertad, democracia y progreso que siempre había defendido el democratismo radical, no encontraran mejor receta que la de preconizar la necesaria desaparición de los partidos. Los últimos, muchas veces inconscientemente y con la mejor de las voluntades, lo propondrán con la doble finalidad de, por un lado, que la soberanía, que entienden se encuentra secuestrada por las cúpulas dirigentes de los partidos, vuelva a ser ejercida directamente, $-\mathrm{y}$ de acuerdo con los presupuestos de aquel mito de la «democracia participativa» que había encontrado en Zampetti uno de sus más brillantes expositores-, por los ciudadanos, y, por otro, que al alejar a las oligarquías partidistas de los órganos de decisión política, los ciudadanos alcances unas mayores cuotas de bienestar.

Es menester advertir que olvidan, sin embargo, éstos que la aparición histórica de los partidos se debió a las necesidades operativas de la izquierda burguesa y obrera (P. De Vega), y, además, como medio ineludible para poder combatir, en el contexto de un sistema político en el que, lejos de operar ese sufragio universal cuya conquista se convertiría en el principal problema de la democracia decimonónica y, en cualquier caso, en uno de los contenidos programáticos fundamentales de las fuerzas de la izquierda democrática ${ }^{64}$, lo hacía el sufragio restringido ${ }^{65}$ — y que, en definitiva, no hacía más que mantener en el primer Estado burgués de Derecho aquella realidad del Estado absoluto en donde, como denunció Fichte, lo

62 Citado por P. De VEGA, «Supuestos históricos, bases sociales y principios políticos en el Derecho Constitucional democrático», Anuario Jurídico, IX (1982), «Memoria del III Congreso Iberoamericano de Derecho Constitucional».

63 Cfr. G. Burdeau, La Démocratie, París, 1966.

64 Cfr., en este sentido, y por todos, P. DE VEGA, «La función legitimadora del Parlamento», en F. Pau Vall (coord.) y otros, Parlamento y opinión pública, Madrid, 1995.

65 A este respecto, $c f r$., por todos, R. SMEND, «Criterios del Derecho electoral en la Teoría alemana del Estado del s. XIX» (1911), en R. SMEND, Constitución y Derecho Constitucional, cit. 
que ocurría es que «el estamento de los grandes poseedores de bienes, [...], serían los únicos y verdaderos propietarios, los únicos ciudadanos que forman el Estado, no siendo los restantes más que simples accesorios, obligados a comprar su reconocimiento al precio que les plazca a los primeros» ${ }^{66}$ - , lo que Lassalle, —a quien, por fichtiano y hegeliano, le corresponde el gran mérito de haber comprendido que el problema para las clases económicamente más menesterosas no era el Estado, sino la falta de fuerza que tenían, por lo menos actuando aisladamente, los partidarios del democratismo, del democratismo radical y del socialismo democrático $\left(\mathrm{H}\right.$. Heller $\left.{ }^{67}\right)$, y que, a la postre, le había conducido a propugnar, como posteriormente haría Heller ${ }^{68}$, la necesidad de llegar a acuerdos, siquiera fueran puntuales, entre estas organizaciones_- había identificado con el rótulo de «férrea ley económica», conforme a la cual la burguesía liberal y conservadora no será proclive a la aprobación de normas jurídicas que favorezcan el bienestar de esa inmensa mayoría de la población que está integrada en la clase no propietaria. Y, ni que decir tiene, este olvido les conduce, inexorablemente, a ignorar que, como señaló Pedro De Vega, la desaparición de los partidos, en cuanto que instrumentos fundamentales para la participación de los ciudadanos en el proceso de toma de decisiones políticas fundamentales, a quienes en realidad favorecería no es a las clases económicamente más necesitadas, sino, muy al contrario, a los propietarios de los medios de producción y financieros, adscritos, de una manera generalizada, a las tendencias más conservadoras y, de cualquier forma, partidarios, también con carácter general, del liberalismo económico.

Y nos interesa resaltar esto, por cuanto que es desde este esquema desde donde se va a producir tanto la denuncia de la actual desaparición de la división de poderes, como la reivindicación a la vuelta a los esquemas formales de la construcción de Montesquieu. Del mismo modo que es también esta circunstancia la que, en último término, nos permite realizar la, ya aludida, equiparación entre las propuestas de los participantes de los movimientos antipartido del presente, con las de los neoliberales y con la de los autores antidemócratas y antiliberales del período de Entre Guerras. En efecto, lo que sucede es que todas estas propuestas conducen a esa situación descrita por De Vega cuando, en 1996, escribió que «La pretensión de reconstruir un orden liberal en el que las instancias políticas [...] cedan su puesto a las instancias sociales, terminará convirtiéndose de esta forma en una crítica directa e injusta de los partidos políticos, de los que sin pudor alguno se denunciarán sus males, y en una apologética indirecta, pero no por ello menos decidida, de los grupos de presión. Se condena a los partidos y se critica su acción, para que en su lugar se desarrolle la actividad de los grupos y de

66 J. G. Fichte, El Estado comercial cerrado. Un ensayo filosófico como apéndice a la doctrina del Derecho, y como muestra de una política a seguir en el futuro (1800), Madrid, 1991.

67 Cfr., en este sentido, H. Heller, «Hegel y la política alemana» (1924), Res Publica, n. ${ }^{\circ} 4,1999$.

68 Cfr. H. Heller, «Estado, Nación y socialdemocracia» (1925), en H. Heller, Escritos políticos, Madrid, 1985. 
los poderes privados. Constituye un hecho perfectamente verificable que en aquellas democracias donde los partidos todavía gozan de un mínimo prestigio, los grupos de presión tienen una acción mucho más limitada que en aquellas otras donde han perdido definitivamente su legitimidad. Hablar, en estas circunstancias, de una reconstrucción de la sociedad liberal, dando por buena la hipótesis de que nos enfrentamos a una sociedad presidida por la acción de los grupos de presión, obliga a conferir la razón a aquel discípulo de Hegel que decía que los grandes acontecimientos históricos se repiten siempre como farsas».

\section{EL ESTADO DE PARTIDOS COMO RAZÓN DE LA PRETENDIDA OBSOLESCENCIA DE LA DOCTRINA DE LA DIVISIÓN DE PODERES}

Punto de partida de todas estas denuncias y reivindicaciones, es el colosal cataclismo que el reconocimiento jurídico del fenómeno partidista generó en el sistema jurídico-formal, que no en el de la realidad político-material — donde las organizaciones políticas partidistas, ignoradas tanto por los prácticos de la política como por los estudiosos del Estado, la Política y el Derecho, acaso por considerar a aquéllas como unos sujetos que, por un lado, se resisten a someterse al Derecho, y, por otro, son capaces de generar el fait accompli, o la fuerza normativa de los hechos, comprendido éste, como lo hacía el ilustre Maestro de Heidelberg ${ }^{69}$, el más lúcido, válido, riguroso y capaz de todos los miembros de la vieja Escuela Alemana de Derecho Público (A. Baldassarre), como un fenómeno histórico con fuerza constituyente, sí operaban-, de la democracia representativa propia del Estado Constitucional liberal. Conmoción que comienza manifestándose en el sentido que hoy tiene el propio discurso parlamentario. En efecto, todos podemos ser conscientes que, en el marco del Estado de partidos y con el sufragio universal ya operante, en donde, como escribió Smend, «El debate parlamentario ha dejado de ser el momento creador de la decisión política para pasar a convertirse cada vez más en una fachada detrás de la que se realizan con toda discreción las negociaciones entre los partidos. Desde que la actividad parlamentaria depende de los grupos parlamentarios, son éstos los que concretan la vida parlamentaria, [...]. Apenas se puede decir ya que nuestro parlamentarismo es un «Government by talking», esto es, una forma de gobierno [como señaló, refiriéndose al modelo británico, Redlich $\left.{ }^{70}\right]$ «se basa en el instrumento de la palabra como motor y fórmula esencial de su ejecución», ya no se trata, como debía suceder en el Parlamento ideal schmittiano ${ }^{71}$, y que en realidad nunca existió (P. De

69 Cfr. G. Jellinek, Reforma y mutación de la Constitución (1906), Madrid, 1991.

70 Cfr. J. Reduich, Recht und Technik des englischen Parlamentarismus: Die Geschäftsordum des House of Commons in ibrer geschichtlichen Entwicklung imd gegenwätigen Gestalt, Leipzig, 1905.

71 Cfr. C. Sснмітт, Sobre el parlamentarismo (1923/1926), Madrid, 1990. 
Vega), de convencer a los otros parlamentarios para encontrar la Razón, la Verdad y la Justicia, sino que de lo que se trata de es de convencer al Cuerpo Electoral. Aunque no terminan aquí las transformaciones del régimen parlamentario debidas al fenómeno partidista.

Nos referimos, más concretamente, a la observación realizada, —y en la que algunos han querido ver no una mera constatación de la realidad política, sino una clara prueba de un claro antiparlamentarismo, similar al mantenido por Schmitt-, en 1919, por Smend, conforme a la cual la aparición del fenómeno partidista determina que frente a ese Parlamento ideal construido, en «Die geistesgeschichlitche Lage des beuting Parlamentarismus», por Schmitt, hoy las Asambleas Legislativas han perdido esa condición prominente que le habían otorgado los primeros liberales, para convertirse, de manera inevitable, y cada vez más, en una fachada en la que se formalizan los acuerdos intra e inter partidos, y en el que, consecuencia de aquel mandato de partido que permitía escribir irónicamente al más brillante y capaz de todos los constitucionalistas positivistas que «Hasta se podría plantear la idea de [...] permitir a los partidos delegar de su propio seno, [.... , los expertos con que pudieran contar para participar en la deliberación y adopción de acuerdos sobre las diversas leyes, expertos que en cada caso influirían en la resolución con el número de votos asignados proporcionalmente a sus respectivos partidos políticos» (H. Kelsen), la mayoría de los parlamentarios se limitan a aprobar las decisiones que previamente se han adoptado en los Comités Ejecutivos de las organizaciones políticas partidistas. Desde esta observación, la denuncia de la «muerte de Montesquieu» en los modernos regímenes parlamentarios no ofrece dificultad alguna para su comprensión. Porque, se dirá, quienes ocupan los Parlamentos son los partidos, y quienes deciden no son los parlamentarios individuales sino sus comités ejecutivos, lo que sucede es que en un sistema donde todos los demás órganos constitucionales son designados por las Asambleas Legislativas, todos los poderes constituidos del Estado van a encontrarse en unas mismas manos: las del partido o partidos que conforman la mayoría parlamentaria. De donde, se dirá también, el sistema de frenos y contrafrenos que implicaba el principio de división de poderes teorizado por Montesquieu, y que fue consagrado en el más alto nivel normativo del Estado desde los grandes procesos revolucionarios liberal-burgueses de finales del s. XVIII, ha dejado de tener vigencia y eficacia en el contexto del Estado Constitucional democrático y social en cuanto que Parteienstaat que es.

\section{LA REFORMULACIÓN DE LA DOCTRINA: CHECK AND BALANCES ENTRE LAS FUERZAS MAYORITARIAS Y LAS DE OPOSICIÓN}

Es menester indicar que la crítica resulta exagerada, y que no justifica ni la proclamación de la muerte del barón de La Brède, ni la de la reivindicación de la vuelta a los esquemas formales trazados por éste. E importa advertir que esto es 
así, incluso desde el punto de vista jurídico-formal. Veámoslo, aunque de manera sintética, con un cierto detenimiento. Es verdad que en el sistema de gobierno parlamentario, en el que una de sus notas definidoras más relevantes es, justamente, la de que el encargado de formar Gobierno será aquél que consiga la confianza de la mayoría del Parlamento - en el actual Derecho Constitucional español, del Congreso de los Diputados-, puede decirse que, frente al modelo diseñado por Montesquieu, en el Estado de partidos es un mismo sujeto, el partido que ocupa la posición de mayoría parlamentaria, quien va a ocupar tanto el Poder Legislativo como el Poder Ejecutivo. De esta suerte, evidente es que lejos de producirse aquella confrontación entre ambos poderes a la que se refería de Secondat, lo que sucede es que, al actuar el partido como correa de transmisión entre uno y otro, sus relaciones van a ser de obligada colaboración.

Ahora bien, si esto es así en cuanto al Ejecutivo y al Legislativo, no es menos cierto que la crítica no se sostiene en relación con los otros poderes constituidos. $\mathrm{Ni}$ siquiera cuando, como es lo usual, sean los partidos políticos con representación parlamentaria quienes proponen a los integrantes de los otros órganos del Estado. Los Magistrados Constitucionales designados por el Congreso de los Diputados y el Senado en el sistema constitucional español, nos ofrecen, - no obstante la perniciosa política de las «cuotas» que todos los partidos denuncian, pero a la quero no están dispuestos a renunciar-, un magnífico ejemplo al respecto. Existen, en efecto, garantías jurídicas bastantes en el Texto Constitucional español para asegurar esa imprescindible independencia de los Magistrados Constitucionales respecto de los partidos que los propusieron. Y no nos referimos tan sólo a la figura del voto particular consagrada en el artículo 164, y que constituye uno de los instrumentos de defensa de la independencia del Magistrado individual (P. De Vega, J. L. Cascajo). A lo que aludimos, de un modo muy principal, es a que difícilmente puede afirmarse que en la España de 1978 un mismo partido político ocupa simultáneamente el Poder Legislativo, el Poder Ejecutivo y el Tribunal Constitucional. Y ello, por la propia mayoría establecida por el Poder Constituyente para la elección de estos Magistrados Constitucionales por las Cámaras parlamentarias, y que, de modo definitivo, asegura la independencia de éstos, aunque no tanto, por la remisión a la Ley Orgánica para la determinación de las funciones, la del propio órgano ${ }^{72}$. A ello se refirió, con la brillantez, rigor y

72 Fue ya P. De Vega quien, en uno de los primeros comentarios al vigente Código Constitucional español, llamó la atención sobre este extremo, y sobre la circunstancia de que la independencia del órgano puede verse comprometida como consecuencia de la desconstitucionalización [sobre la figura de la desconstitucionalización, $c f r$. , por todos, N. PÉREz SERRANO, «El problema de la "desconstitucionalización” ", Boletín Informativo del Seminario de Derecho Político de la Universidad de Salamanca, n. ${ }^{\circ}$, 1955], operada por el Legislador Constituyente de 1977-1978 en el art. 161. 1. d). Y lo hizo, señalando, en primera instancia, que «Lo cual es, jurídicamente, inadmisible por la desconstitucionalización tácita que supone del sistema de competencias, y, políticamente, peligroso en la medida que puede afectar al principio de funcionalidad a que se hace referencia en el comentario del artículo 159», para añadir, a continuación, que «Nada se dice, por ejemplo, de la posibilidad o no, de reelección de los magistrados constitucionales. En cualquier caso, lo importante es 
contundencia que le fueron siempre característicos, De Vega. Escribió, a este respecto, y en $1984^{73}$, que «No obstante, y a pesar de estas enfáticas y solemnes declaraciones de independencia, no han faltado una serie de críticas que, [.... , se han vertido contra ella. El argumento de fondo ha sido siempre el mismo: la forma de designación de los miembros del Tribunal, [...] El hecho de que las Cámaras y el Gobierno _ [ [...]_ propongan a diez de los doce Magistrados que componen el Tribunal, ha servido para que, con una simpleza digna de mejor causa, se llegue a afirmar que el Tribunal Constitucional, lejos de ser independiente, forzosamente habrá de convertirse en un puro mandatario de los órganos que los designan. [...] A parte de los datos que la experiencia ofrece, [...], existe otra circunstancia que no se puede olvidar. La designación de los componentes del Tribunal se efectúa por una mayoría de tres quintos de parlamentarios, lo que

destacar que a la Ley orgánica que regule el funcionamiento del Tribunal va a corresponderle la decisiva tarea de estructurar toda la mecánica de la justicia constitucional, de la que, en el presente título, sólo se esbozan los rasgos y supuestos fundamentales. Surge así una aporía que convierte al artículo 165, aparentemente sin relevancia, en uno de los puntos técnicamente más críticos y conflictivos de todo nuestro ordenamiento constitucional. El problema es el siguiente: si corresponde a la justicia constitucional, como guardián de la Constitución, defender el carácter de Ley Suprema de la misma, frente a posibles ataques del poder legislativo (recurso de inconstitucionalidad de las leyes), ¿no podría suceder que, al ser el poder legislativo quien establece en la ley orgánica los procedimientos y formas ante el Tribunal Constitucional, condicionara las actuaciones de éste? Por su propia naturaleza de Norma Normarum las Constituciones deben ser breves. Lo que significa que su contenido debe desarrollarse por leyes posteriores de rango inferior. Ahora bien, la obligada independencia del Tribunal Constitucional impone no sólo la independencia individual de los miembros que lo componen, y a la que se alude en el artículo 159, sino también la independencia funcional como órgano colegiado. Y he aquí la cuestión: ¿es posible hablar de autonomía de la justicia constitucional, encargada de velar de que el contenido de las leyes no vaya en contra de la Constitución, cuando con una simple ley pueden modificarse los supuestos básicos de su estructura y funcionamiento? Para resolver esta dificultad, en otros países, como Italia, se ha apelado, con indudable acierto (artículo 137 de su Constitución), a la creación de una reserva de ley constitucional para la ley encargada de regular el Tribunal Constitucional. En nuestra Constitución se prevé solamente el rango de Ley Orgánica para las disposiciones en que se desarrolle el Tribunal Constitucional. Es verdad que las Leyes Orgánicas requieren unas mayorías cualificadas para su aprobación, como determina el artículo 81, con lo cual, una mínima garantía de que la justicia constitucional no va a ser fácilmente manipulada desde el Parlamento queda asegurada. Sin embargo, la pregunta sigue en pie: ¿no hubiera sido más correcto convertir la ley reguladora del Tribunal Constitucional en una ley constitucional, para cuya modificación se exigieran los requisitos establecidos para la reforma de la Constitución? En buena lógica jurídica así lo exigían los principios que están en la base de la justicia constitucional en los ordenamientos democráticos contemporáneos».

$73 \mathrm{La}$ fecha es relevante por cuanto que en el momento en el que escribe P. De Vega se encontraba vigente la LO 1/1980, del CGPJ, que atribuía la elección de los 12 vocales elegidos entre Jueces y Magistrados de todas las categorías judiciales a los propios Jueces y Magistrados. Solución que sería cambiada en la LO 6/1985, de 1 de julio, del Poder Judical, en la que se estableció que todos los vocales del CGP serían elegidos por las Cortes Generales, debiendo, en todo caso, respetar la previsión constitucional de que 12 de ellos habrían de ser Jueces y Magistrados de todas las categorías judiciales, y 8 juristas de reconocida competencia y con 15 años de antigüedad en el ejercicio de su profesión. Cambio legislativo éste que dio origen a la presentación por parte de quien era el Presidente del CGPJ, F. C. Sainz de Robles, de un conflicto entre órganos ante el Tribunal Constitucional. Conflicto que fue resuelto por la STC 108/1986, en el sentido de que la solución adoptada por la LO 6/1985 era plenamente conforme con la Constitución en la medida en que respetaba la composición del órgano fijada en la Constitución. Cfr. STC 108/1986, FJ 13. De cualquiera de las maneras, y esto es lo que nos interesaba resaltar en esta nota, es esta circunstancia la que explica que en su texto De Vega se refiera tan sólo a los Magistrados designados por las Cámaras parlamentarias y el Gobierno. 
significa que se hace necesario el consenso de los distintos partidos con representación en las Cámaras para llevarla a cabo. Con lo que se asegura, por un lado, que los Magistrados no respondan a concepciones ideológicas monolíticas, y, por otro lado, que, a nivel personal, no tengan que sentirse vinculados a tendencias, ni a partidos concretos».

Señalar esto, conviene aclararlo, en modo alguno significa negar que el fenómeno partidista ha generado un colosal cataclismo en el esquema formal de la división de poderes constitucionalizada desde los grandes procesos revolucionarios liberal-burgueses de finales del s. XVIII, y que, nadie puede ignorarlo, continúa siendo consagrada formalmente en el Estado Constitucional democrático y social. Lo que ocurre, es que la constatación de este hecho no autoriza ni a decretar la muerte de Montesquieu, ni tampoco a exigir la vuelta a los estrictos términos formales en los que de Secondat había teorizado este principio. Y mucho menos, a hacerlo en nombre de la lógica del progresismo y del democratismo. La razón es fácilmente comprensible. La misma, es la de que quienes proponen esta vuelta a los esquemas formales del Estado Constitucional liberal ignoran que en el marco del Estado Constitucional democrático y social, en el que su configuración como Estado de partidos es ya insoslayable, el principio de división de poderes sigue siendo eficaz en tanto en cuanto que el mismo no se articula ya como aquella confrontación imaginada por Montesquieu entre Poder Legislativo, Poder Ejecutivo y Poder Judicial, y, más precisamente, y en la medida en que el aristócrata liberal se encargó de configurar al Poder Judicial como un poder políticamente neutro, entre los dos primeros, sino que, por el contrario, lo que sucede es que, como ha escrito Pedro De Vega, el «juego de fuerzas políticas no se contrapesa ya entre el legislativo y el ejecutivo, habida cuenta que los partidos electoralmente triunfantes suelen estar en ambos, sino entre mayorías y minorías, entre los partidos que ganan las elecciones, pero pueden perderlas en el futuro, y los partidos que pierden las elecciones, pero en una próxima convocatoria pueden resultar vencedores $»^{74}$.

Lo anterior, como ha de ser obvio, no hace sino poner de manifiesto la propia esencia de la Democracia Constitucional. Lo que no ha de ser muy difícil de comprender, y compartir. Nadie puede, en efecto, negar que el principio de división de poderes ha sufrido, y como consecuencia directa e inmediata de la consolidación del fenómeno partidista, una mutación en cuanto a su articulación real. Esto es lo que significa que dicho principio no se materialice hoy en la confrontación entre el Poder Legislativo y el Poder Ejecutivo, sino como el sistema de pesos y contrapesos entre las mayorías y minorías parlamentarias. Ahora bien, lo que no puede perderse de vista es que dicha transformación responde inequívocamente, y de ahí su plena validez y legitimidad, a la esencia misma de la Democracia Constitucional, $-\mathrm{y}$ a pesar de que esto se encuentre, de una u otra suerte, cuestionado por el

74 P. De VEGA, «Jurisdicción constitucional y crisis de la Constitución», REP, n. ${ }^{\circ}$ 7, 1979. 
proceso de globalización, en el que, de forma más que lamentable, se está operando la confrontación entre la capacidad de decisión de los técnicos y la de los ciudadanos-, en cuanto que la misma se define, como, de cualquiera de las maneras, fue puesto de relieve, desde las más diversas concepciones ideológicas y posicionamientos políticos, por tratadistas de las Ciencias Constitucionales tan relevantes como fueron, por ejemplo, un Kelsen ${ }^{75}$, un Friedrich o un De Vega, por ser no el reino de la unanimidad, que es lo propio de los regímenes autocráticos (C. J. Friedrich), sino el de la discusión y la discrepancia, en cuyo seno los distintos operadores políticos del Estado han de verse obligados a llegar a acuerdos desde el desacuerdo en lo fundamental. Y es que, en todo caso, lo que refleja el juego mayorías-minorías no es otra cosa que la importancia que tiene la oposición política para la configuración del propio régimen de la Democracia Constitucional, y de su posibilidad misma, en tanto en cuanto que «en Democracia no es el poder quien ha de dar, y reconocer, la legitimidad a la oposición, sino que, muy al contrario, es la existencia y la actuación de la oposición la que, en último término, confiere legitimidad al sistema, y al partido que gobierna» ${ }^{76}$.

De todos modos, lo que nos interesaba destacar, es que, porque esto es así, surge ante nosotros una clara, y meridiana, conclusión que no podríamos dejar de consignar en este trabajo. Y que no puede resultar más patente y evidente. Sobre todo, para todos aquellos constitucionalistas que acepten que tenía razón Heller ${ }^{77}$ cuando afirmó que la democracia, en el orden histórico y en el de las ideas, nunca está, ni, además, puede estar, en crisis, aunque, de manera indiscutible, lo que sí puede producirse, y de hecho se produce, es la crisis en la gestión de la democracia. Ésta, en definitiva, no es otra que la de que muy en contra de lo que mantuvo el pensamiento antipartido clásico, y lo que sigue afirmando hoy el movimiento antipartido, el pluripartidismo se convierte en el último mecanismo para hacer real y efectivo la división de poderes, así como del resto de los principios inspiradores del constitucionalismo, en la actual democracia de masas ${ }^{78}$.

La mejor prueba de que esto es así, acaso nos la pueda proporcionar esa independencia judicial, que, nadie puede desconocerlo, se encuentra hoy tan cuestionada en la España de 1978, y por el motivo de que, desde la aprobación de la LO 6/1985, de 1 de julio, del Poder Judical, todos los miembros del Consejo General del Poder Judicial, —que, como especifica la Constitución, es tan sólo «el órgano de gobierno del mismo»—, son elegidos por las Cortes Generales ${ }^{79}$. Pero que, de

75 Cfr. H. Kelsen, «Forma de Estado y visión del mundo» (1933), recogido en O. Correas (comp.), El otro Kelsen. México, 1989.

76 J. Ruipérez Alamillo, «Estado social versus aldea global», en J. M. SERnA DE LA GarZA (coord.) y otros, Metodología del Derecho Comparado. Memoria del Congreso Internacional culturas y sistemas jurídicos comparados, México, 2005.

77 Cfr. H. Heller, Las ideas políticas contemporáneas (1926), Granada, 2004.

78 Cfr. H. Heller, «Europa y el fascismo» (1929), en H. Heller, Escritos políticos, cit.

79 Sobre esto, así como la reivindicación de volver a los esquemas formales de Montesquieu sobre la división de poderes, resulta en extremo clarificador P. DE VEGA, «Confusión judicial», ABC, 13 de febrero de 2001. 
cualquiera de las maneras, no es un fenómeno desconocido en otras latitudes, aunque por otros motivos, el que se trate de «resucitar» a de Secondat. Y es que, en efecto, también la independencia judicial va a terminar dependiendo de que exista el pluripartidismo.

Interesa recordar que la, universalmente, proclamada independencia del juez, que, en primer término, está fundamentada en la circunstancia de que éste se encuentra sólo sometido al imperio de la ley, y que, desde el punto de vista jurídico-formal, encuentra su garantía en el hecho de que el ordenamiento constitucional consagre el principio de división de poderes, conforme al cual el juez no se encuentra sujeto a la voluntad ni del órgano encargado de personalizar el Poder Legislativo, y, por ello mismo, desde una posición de una cierta superioridad respecto del resto de los órganos constitucionales en cuanto que es el que ejerce la función legislativa del Pueblo por la elección directa del Cuerpo Electoral (H. Heller), ni del órgano que se presenta como el titular del Poder Ejecutivo. Lo que, de algún modo, va a concretarse en el principio de que éstos, como se desprende del mismo tenor literal del artículo 117. 2, no podrán, a diferencia de lo que sucedía en el Antiguo Régimen, ni separar, ni suspender libremente a los jueces y magistrados.

Ahora bien, con lo que nos encontramos es con que la efectividad real de la independencia del juez depende, y desde el punto de vista de la realidad política y jurídica, mucho más que de las previsiones contenidas en la Constitución, de lo que realmente sucede en la vida política de la misma. Dicho de una manera mucho más contundente, nos encontramos con que el juez, sujeto tan sólo al imperio de la ley y no a la voluntad de los gobernantes, será realmente independiente cuando en el Estado de que se trate opere un sistema multipartidista. Y ello, por cuanto que es en virtud del pluripartidismo cuando el principio de división de poderes, cuya formulación clásica, como ya hemos señalado, pero no importa insistir en ello, «ha sido sustituida por una nueva y diferente forma de equilibrio. El juego de pesos y contrapesos (checks and balances) entre los poderes del Estado no se produce ya entre el Legislativo y el Ejecutivo, [...], sino entre mayorías y minorías, entre los partidos que ganan las elecciones, pero pueden perderlas en el futuro, y los partidos que pierden las elecciones, pero en una próxima convocatoria pueden resultar vencedores» (P. De Vega), adquirirá una entidad y efectividad reales y podrá desplegar toda su potencialidad. Lo que nos dice que, por mucho que la misma se encuentre enfática y solemnemente proclamada por el Derecho Constitucional vigente, la independencia de los jueces, como órganos encargados de ejercer la función jurisdiccional en el Estado, no pasará de ser una mera declaración retórica y, al mismo tiempo, absolutamente vacía de contenido en aquellos Estados donde el pluripartidismo no existe. Y, lógicamente, esto encontrará su máxima expresión en el caso de los Estados autocráticos, en los que, en muy buena medida como consecuencia de la incapacidad que tienen todos los autócratas para reconocer que la realidad no es unidimensional y que, por ello mismo, es fuente de conflictos (P. De Vega), el partido del que 
se vale el autócrata no sólo es el único que opera en ese determinado Cuerpo Político, sino que se integra en la propia maquinaria del Estado. Con la sagacidad y penetración que siempre le fueron característicos, Heller, en su estudio-denuncia sobre el régimen político y jurídico del totalitarismo fascista en Italia, puso de relieve, y con toda contundencia claridad, esta circunstancia. Y creemos, en todo caso, que, aunque la cita sea larga, merece la pena transcribir sus palabras. Señala Heller que «La concentración descrita del Poder ejecutivo y legislativo en las manos del dictador da también al traste con la independencia que el Poder judicial tiene en el Estado de derecho. La independencia de los jueces es sólo un corolario de su dependencia de la ley, entendiendo por ley en el Estado de derecho aquella norma jurídica suprema elaborada, por lo menos con la cooperación del Poder legislativo del pueblo, [...] En el sistema del Estado de derecho la garantía de justicia relativa de la ley estriba en todo el procedimiento legislativo, a través del cual deben expresarse y completarse, con la mayor libertad e igualdad posibles, todas las valoraciones que viven en el pueblo. [...] Cuando el dictador concentra en sus manos el Poder legislativo y cuando todas las normas jurídicas superiores emanan más o menos exclusivamente de su voluntad [que era lo que sucedía en la Italia de Mussolini], el juez no depende ya de las leyes, sino de la voluntad actual del dictador y, por tanto, la administración de justicia es también dictatorial».

No trataba yo, como es lógico, de dar en estas líneas una solución definitiva a la problemática actual de la división de poderes. Entre otras cosas, por cuanto que soy plenamente consciente de que mi discurso deja, por razones de espacio, de atender el problema de la eficacia de este principio en el marco del Estado social, en donde, necesariamente, éste ha de presentarse como el diálogo entre el poder público, al que le corresponde la defensa de la libertad de los ciudadanos, y el poder privado, así como su realidad, o, más bien, su no materialización en un mundo globalizado, en el que la vida política se hace depender de las diversas «guerras comerciales». Lo que, por el contrario, trataba, era simplemente de aportar algunos elementos para la reflexión sobre un problema que, querámoslo o no, sigue siendo medular para el Derecho Constitucional en el s. XXI. Y sobre el que, necesariamente, los constitucionalistas tendremos que seguir reflexionando, siquiera sea para hacer frente a nuestra principal tarea profesional, que no es otra que la de la explicación de la Democracia Constitucional, y su defensa, desde el entendimiento de que, por decirlo en palabras de Maestro Pedro De Vega, «No podemos los constitucionalistas, como aquellos médicos reales, de los que hablaba Quevedo, que ocultaban las enfermedades de los reyes y las convertían en enigmas, ocultar los problemas de la vida constitucional haciendo de ellos auténticos misterios. Sólo de este modo nos veremos liberados de correr igual suerte que la de los galenos de Corte para quienes la enfermedad de los reyes solo existía dos días: el día que eran requeridos para curarles y el día que decretaban su muerte. Triste sería el oficio de constitucionalista si el entusiasmo en los comienzos de un régimen democrático se transformara luego en silencios 


\section{culposos de sus problemas, para terminar — como en ocasiones ha ocurrido- constatando con exaltación su final».}

$$
* * *
$$

TITLE: Charles de Secondat in the State Parties

ABSTRACT: No one can doubt the importance of the doctrine of division of powers, in the formulation made by Montesquieu, for the modern Constitutional State. However, few also will ignore that the virtuallity to explain the power relations in the current States, characterized as "State of Parties» (Triepel) has been questioned, in the context of a broader crisis of representative Democracies. This paper argues that, inasmuch as political parties are indispensable elements of our democratic system, the classic distinction between legislative, executive and judicial power enunciated by the Baron de la Brède must be understood together with the set of checks and balances (vetoes) that it occurs in relations between government and opposition.

Resumen: Nadie puede dudar de la importancia de la doctrina de la división de poderes, en la formulación realizada por Montesquieu, para el moderno Estado Constitucional. Sin embargo, también pocos desconocerán que la virtualidad para explicar las relaciones de poder en los Estados actuales, caracterizados como «Estados de Partidos» (Triepel) ha venido siendo puesta en duda, en el marco de una más amplia crisis de las Democracias representativas. Este trabajo sostiene que, dado que los partidos políticos resultan elementos indispensables de nuestro sistema democrático, la clásica distinción entre poder legislativo, ejecutivo y judicial enunciada por el Barón de la Brède ha de comprenderse conjuntamente con el juego de pesos y contrapesos (vetos) que se produce en las relaciones entre Gobierno y Oposición.

KEY WORDS: Division of powers; political parties; constitutional justice; political opposition.

Palabras Clave: División de poderes; partidos políticos; justicia constitucional; oposición política.

FECHA DE RECEPCión: 20.11.2019 FECHA DE ACEPTACión: 09.09.2020 